\title{
The influence of location, planning and design features on residents' satisfaction with security in public housing estates in Lagos, Nigeria
}

\begin{abstract}
Location, planning and design of the built environment are known to have influence on the security of lives and property in residential neighbourhoods. However, there is a limited understanding of the extent to which these aspects contribute to security in public housing environments in a developing country like Nigeria. This study investigated the influence of locational, planning and design features on residents' perception of security in public housing estates in Lagos metropolis, Nigeria. The data used were derived from a questionnaire survey of 1036 residents in 12 Lagos State Development and Property Corporation (LSDPC) housing estates in the study area. Results of the descriptive statistics, factor and regression analyses revealed that the residents were generally satisfied with security of lives and property in the housing estates. Provisions for communal living, layouts of the estates and passive security measures and location of the estates close to neighbourhood facilities and in crime prone areas of the city contributed most to residents' perception of security in the estates. This study implies that to enhance security in public housing environments, priority should be given to location, planning and design strategies that promote communal living and residents' participation in the security of their homes.
\end{abstract}

Keywords: Crime prevention through environmental design, Defensible space, Household survey; Lagos; Public housing, Security 